\title{
Effects of Childbirth Education on Prenatal Adaptation, Prenatal and Maternal Attachment
}

\author{
(1) Nevin Çıtak Bilgin, ${ }^{1}$ (D) Bedriye Ak, (1) Fatma Ayhan, ${ }^{1}$ (1) Fatma Öztürk Koçyiğit, ${ }^{2}$ \\ (1) Songül Yorgun, ${ }^{2}$ (1) Mehmet Ata Topçuoğlu ${ }^{3}$ \\ 'Department of Nursing, Bolu Abant İzet Baysal University Faculty of Health Sciences, Bolu, Turkey \\ ${ }^{2}$ Department of Nursing, Bolu İzzet Baysal State Hospital, Bolu, Turkey \\ ${ }^{3}$ Department of Obstetrics and Gynecology, Bolu Abant İzzet Baysal University Faculty of Medicine, Bolu, Turkey
}

Please cite this article as: Çıtak Bilgin N, Ak B, Ayhan F, Öztürk Koçyiğit F, Yorgun $S$, Topçuoğlu MA. Effects of Childbirth Education on Prenatal Adaptation, Prenatal and Maternal Attachment. Anatol J Family Med 2020;3(2):128-135.

Address for correspondence: Dr. Nevin Çıtak Bilgin. Department of Nursing, Bolu Abant İzzet Baysal University Faculty of Health Sciences, Bolu, Turkey

Phone: +90 3742541000

E-mail:nevincitak@yahoo.com

Received Date: 30.09.2019

Accepted Date: 31.03.2020

Published online: 21.08 .2020

(C) Copyright 2019 by Anatolian Journal of Family Medicine -

Available online at www.anatoljfm.org

OPEN ACCESS

\section{ABSTRACT}

Objectives: Pregnant women's problems in prenatal adaptation and maternal attachment negatively affect the health of the mother, family and the baby. Childbirth education may increase adaptation to pregnancy by increasing women's self-confidence and help strengthen the bonds with their babies. This study aimed to investigate the effects of childbirth education on prenatal adaptation, prenatal and maternal attachment.

Methods: This study was with pre/post-education, semi-experimental and prospective design. Research data were collected using the Participant Identification Form, Prenatal Self Evaluation Questionnaire, Prenatal Attachment Inventory and Maternal Attachment Inventory.

Results: A total of 173 women, 90 (52.0\%) in the education group and 83 (48.0\%) in the control group, participated in the study. The prenatal and prenatal attachment adaptation levels of the control and education group were found to be similar before this study $(p=0.770$ and $p=0.277$, respectively). Pregnant women's prenatal adaptation increased after education and between-group differences were significant $(p<0.001)$. Prenatal attachment level also increased in the education group after education $(p<0.001)$. However, prenatal and maternal attachment levels were similar between groups ( $p=0.171$ and $p=0.763$, respectively).

Conclusion: It was identified that childbirth education increased prenatal adaptation but did not affect prenatal and maternal attachment. Childbirth education routinely provided as a part of antenatal care by health professionals ensures awareness in parenting by increasing prenatal adaptation.

Keywords: Emotional bonds, maternal health, prenatal care

\section{INTRODUCTION}

The main aim of childbirth education is to develop pregnant women's health-related behaviors, increase their self-confidence and prepare the couples for childbirth and parenting ${ }^{[1-4]}$ According to one of the various definitions, motherhood is a process that starts with pregnancy and birth and continues throughout life. ${ }^{[5]}$ The prenatal adaptation is important during this period. ${ }^{[6,7]}$ When the expecting mother cannot adapt to the prenatal period, the process of accepting the pregnancy may lengthen and the mother-to-be may develop negative attitudes towards the pregnancy and the baby as a result of the physical and psycho-social problems she experiences. ${ }^{[8,9]}$

Establishing the attachment between the mother and the fetus during the prenatal period is critical for the cognitive, psycho-social and emotional development of the baby. ${ }^{[10]}$ Studies showed that childbirth education affected the levels of attachment positively and interact- 
ing with the fetus, establishing contact with the baby by touching the belly and imagining and talking to the baby during education increased attachment. ${ }^{[9,11,12]}$

The mother is the key in the attachment relationship and prenatal attachment is significant for postpartum maternal attachment. ${ }^{[12,13]}$ Maternal attachment is an indicator of prenatal attachment and it is related to health practices and education during the prenatal period. ${ }^{[14-16]}$ Childbirth education programs are not so common and standardized within the prenatal period in Turkey. These programs mostly focus on physical care and psychological aspects of maternal-fetal attachment are hardly included. ${ }^{[17]}$

Previous studies explored the effects of childbirth education on prenatal adaptation, prenatal attachment and maternal attachment. ${ }^{[16,18-21]}$ However, to our knowledge, there is not research in the literature that investigated the effect of childbirth education on prenatal adaptation and attachment during pregnancy and on postpartum maternal attachment together by comparing the education group (EG) and control group (CG), and therefore, this study was designed to address this issue.

This study utilized a pre/post-education, semi-experimental and prospective design with EG and CG to investigate the effects of childbirth education on prenatal adaptation and attachment and maternal attachment. This study tested the hypotheses provided below:

1. There is a difference between prenatal adaptation level of pregnant women participating and not participating in childbirth education.

2. There is a difference between prenatal attachment level of pregnant women participating and not participating in childbirth education.

3. There is a difference between maternal attachment level of pregnant women participating and not participating in childbirth education.

\section{METHOD}

\section{Study Setting and Sample}

The universe of this study was composed of pregnant women who applied to the Maternity Hospital in a province situated in the northwest of Turkey. Eighteen years or over, at least primary school graduate, speak and understand Turkish, being nulliparous, carrying a single fetus, being at $24^{\text {th }}-32^{\text {nd }}$ week of pregnancy with no complications were included into the study. The study sample consisted of two groups. EG composed of pregnant women who applied to participate in the hospital's childbirth education classes. CG was composed of pregnant women who came in for routine controls (such as physical, ultrasound) and did not participate in childbirth classes. There was no intervention in the CG except routine care and information during routine pregnancy.

The sample size was calculated using power analysis. By accepting a $5 \%$ error rate and $85 \%$ power along with differences between expected means for prenatal adaptation as 6.8 and standard deviation as 19.3 in power analysis, the sample size for each group was calculated to be 104 . ${ }^{[18]}$ Losses were expected, so 150, and 170 pregnant women were registered in EG and CG, respectively. This study included the pregnancy period and covered the first-month post-partum.

\section{Data Collection}

Research data were collected using the Participant Identification Form developed by the researchers, Prenatal Self Evaluation Questionnaire (PSEQ), Prenatal Attachment Inventory (PAI) and Maternal Attachment Inventory (MAI).

\section{Participant Identification Form}

The form prepared by the researchers in line with relevant literature includes questions on socio-demographic qualities (age, level of education, work status, duration of marriage) and obstetric characteristics (whether the pregnancy was planned, gestational week, type of pregnancy).

\section{The Prenatal Self Evaluation Questionnaire}

The PSEQ was developed by Lederman et al. to assess pregnant women's adaptation to pregnancy and the motherhood role. ${ }^{[22]}$ Beydağ et al. carried out the reliability and validity studies of the questionnaire in Turkey. ${ }^{[6]}$ PSEQ is composed of 79 items and seven sub-scales: concern for the well-being of self and baby, acceptance of pregnancy, identification of a motherhood role, preparation for labor, fear of labor, relationship with own mother and relationship with husband. The 4-point Likert scale (1: not at all, 2: somewhat, 3: moderately so and 4:very much so) has the lowest score of 79 and the highest score of 316. Low scores point to high prenatal adaptation. The Cronbach's alpha coefficient of the scale is 0.81 and it was found as 0.89 for this study.

\section{Prenatal Attachment Inventory}

PAI was developed in 1993 by Muller. ${ }^{[23]}$ The scale, which is developed to explain the thoughts, feelings and situations that women experience during pregnancy and to determine the prenatal attachment levels to their babies, consists of 21 items. The scale was adapted for use in Turkey by Yilmaz et al. and there has been a good internal consistency ( $a=0.84)$, which was also found in the current study 
$(\mathrm{a}=0.88) .{ }^{[15]}$ The 4-point Likert scale (1: never, 2: sometimes, 3: often, 4: always) provides the lowest score of 21 and the highest score of 84 . High scores indicate an increased level of attachment.

\section{Maternal Attachment Inventory}

MAI was developed by Muller to evaluate the maternal emotions and behaviors that point to affective attachment of mothers to their infants. ${ }^{[24]}$ Kavlak et al. carried out the reliability and validity studies of the inventory in 2009 in Turkey. ${ }^{[25]}$ MAl is a 4-point Likert scale (never: 1 , sometimes: 2, often: 3 and always: 4) with 26 items. High scores point to the high levels of maternal attachment. The lowest score that can be obtained is 26 , and the highest score is 104 . The Cronbach's alpha coefficient of the scale of Kavlak et al. was 0.77 , and it was determined to be 0.69 in this study. ${ }^{[25]}$

\section{Stages of this Study}

This study was carried out in three stages (Figure 1).

\section{First Stage}

The education was announced at the antenatal and gynecology clinics of the hospital. The pregnant women between 24 and 32 weeks of gestation and who wanted to participate in the education were included in the EG, and the pregnant women who continued routine antenatal follow-up were included in the CG. Demographic data forms, PSEQ and PAI were applied to the EG before starting the education and to the CG during the outpatient follow-up visits. A childbirth education was given to women in EG once a week for three hours lasted for five weeks. CG continued routine monitoring.

\section{Second Stage}

PSEQ and PAI forms were applied face-to-face to the pregnant women in EG and CG five weeks after the first followup (between 29-36 weeks of gestation).

\section{Third Stage}

MAI was applied to women in EG and CG using telephone one month after the delivery.

\section{Implementation of Education for EG}

A room was designed to deliver education. The room was equipped with pillows, mats, models related to fetus and birth, Pilates balls, walls covered with affirmation sentences and visuals about the fetus and the birth.

Education was conducted once a week (09.00-12.00 AM) for five weeks' duration. Each course lasted 15 hours and was done with a maximum of 10-12 participants. The education was provided from September 2015 to June 2017.

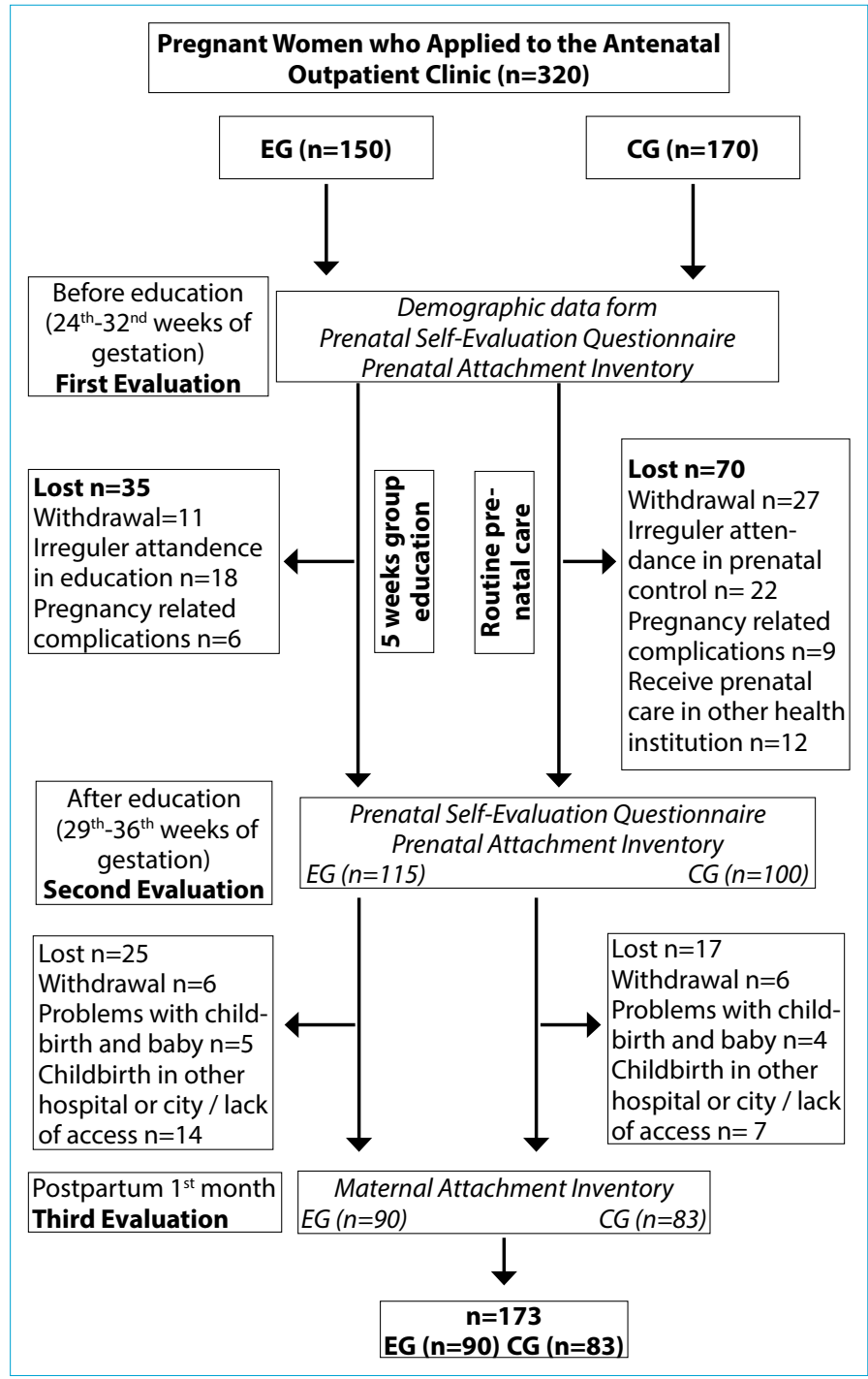

Figure 1. Study flow chart.

EG: Education group; CG: Control group.

Visual tools, models and video demonstrations were utilized in the education. Presentations and interactive education methods were also used. Breathing and relaxation exercises were conducted at the end of each 30-45 minutes session. Baby and birth-related affirmations were given to the participants. They were asked to repeat these exercises and affirmations at home daily. Education was provided by first author Nevin Çıtak Bilgin with childbirth trainer certificate and the midwife Fatma Koçyiğit responsible for the childbirth class. Childbirth Educational Program consisted of the following basic issues weekly:

$1^{\text {st }}$ week: Physiology of delivery, indications of birth, fear of birth, relaxation techniques,

$2^{\text {nd }}$ week: Stages of delivery, effects of hormones at birth, emotional and physical support, the importance 
of communicating with the baby on the mother's womb, the effects of relaxation on maternal and fetal.

$3^{\text {rd }}$ week: Non-drug relaxing techniques to cope with birth pain.

$4^{\text {th }}$ week: Anesthesia at birth, interventions for delivery, making a birth plan.

$5^{\text {th }}$ week: Mother-infant relationship, baby care, breastfeeding.

A maternity and postpartum clinical visit was conducted with the candidates of the mothers at the end of five weeks of education.

\section{Exclusion Criteria}

During education, pregnant women in EG who did not attend the 5-week education regularly and pregnant women who developed complications during the education process. Pregnant women in CG who did not come for a checkup at the $5^{\text {th }}$ week following the first interview and pregnant women in CG who did not fill in the surveys again at the 5th week following the first interview and pregnant women in CG who developed any complications related to pregnancy during the 5-week time frame. Also, women who had early ( $<37$ weeks) or post-term ( $>42$ weeks) birth and women whose babies were in the newborn unit were excluded from this study in EG and CG.

\section{Data Analysis}

SPSS 22.0 program was used for the data analysis. Frequency, percentage, mean and standard deviation were used as descriptive statistical analysis. Cronbach alpha internal consistency was calculated in the reliability analysis of data collection tools. The skewness and kurtosis values were examined to decide whether data showed normal distribution. In this study, the mean scores for PSEQ (skewness 0.390 and kurtosis 0.426 ), PAI (skewness -0.848 and kurtosis 0.839 ) and MAI (skewness 1.140 and kurtosis 0.213 ) displayed normal distribution. ${ }^{[26]}$ Student t-test and chi-square tests were used to investigate whether there was a difference between groups concerning demographic variables. T-tests were used to compare EG's and CG's PSEQ, PAI and MAI mean scores. Within-group comparison, t-test was used in dependent groups. The statistical significance level was accepted as $p<0.05$ for all statistical analyzes.

\section{RESULTS}

This study was completed with a total of 173 mothers who gave birth, 90 (52.0\%) in EG and 83 (48.0\%) in CG (Figure 1).

Table 1 shows a comparison of demographic and obstet- ric characteristics of pregnant women included in the EG and CG. There was no statistically significant difference between groups in terms of age, duration of the marriage, gestational week, employment, the status of planned pregnancy and pregnancy type $(p>0.05)$. However, there was a significant difference in educational status between women in EG and CG $(p<0.001)$. In this study, $80(69.5 \%)$ of the women in the EG and 33 (33.0\%) of the women in the CG were university graduates.

Table 2 presents the first and second evaluations concerning the comparison of between-group PSEQ and PAI mean scores. There were no significant between-group differences in PSEQ and PAI mean scores between the EG and CG before education ( $p>0.05$ ). In the second evaluation, the mean PSEQ score was identified to be lower in EG compared to $C G$ and the difference was statistically significant $(p<0.001)$. The decrease in PSEQ scores indicates increased prenatal adaptation. There were no statistically significant between-group differences in PAI mean scores $(p>0.05)$. Education improved prenatal adaptation and did not affect prenatal attachment.

Within-group comparisons of pre- and post-education, PSEQ and PAI mean scores for pregnant women are presented in Table 3. The mean PSEQ and PAI scores for EG were found to increase after education compared to the pre-education level with a significant difference $(p<0.001)$. No similar and statistically significant differences were identified for PSEQ and PAI mean scores for the first and second evaluations in CG ( $p>0.05)$. The findings showed that education increased prenatal adaptation and prenatal attachment in the intervention/treatment group while there was no difference in the CG.

When maternal attachment levels were compared between groups one month after giving birth, the mean MAI scores were identified to be similar in the EG and CG, and no statistically significant between-group differences were detected (101.8 \pm 2.6 vs. $101.9 \pm 3.0, p=0.763)$.

\section{DISCUSSION}

This study aimed to investigate the effects of childbirth education on prenatal adaptation and maternal attachment. It was observed that groups were similar concerning demographic and obstetric characteristics other than the variable of educational status. While a little more than half of the participants in EG were university graduates, only one-third of the participating women in the CG graduated from a university. Similar studies showed that the majority of women participating in childbirth education were university graduates. ${ }^{[4,27,28]}$ The difference found between 
Table 1. Comparison of demographic and obstetric characteristics of pregnant women in education and control groups

\begin{tabular}{|c|c|c|c|c|}
\hline Characteristics & $\begin{array}{l}\text { Education group } \\
\qquad \begin{array}{c}(n=115) \\
\text { Mean } \pm S D\end{array}\end{array}$ & $\begin{array}{l}\text { Control group } \\
\qquad \begin{array}{c}(n=100) \\
\text { Mean } \pm S D\end{array}\end{array}$ & $\mathbf{t}$ & $\mathbf{p}^{*}$ \\
\hline Marriage duration (years) & $2.5 \pm 1.6$ & $2.9 \pm 2.2$ & 1.745 & 0.083 \\
\hline Gestational week (weeks) & $28.6 \pm 3.4$ & $28.7 \pm 2.0$ & 0.123 & 0.902 \\
\hline \multicolumn{5}{|l|}{ Education } \\
\hline Primary education & $11(9.6)$ & $36(36.0)$ & 32.851 & $<0.001^{+}$ \\
\hline High School & $24(20.9)$ & $31(31.0)$ & & \\
\hline University & $80(69.5)$ & $33(33.0)$ & & \\
\hline \multicolumn{5}{|l|}{ Employment } \\
\hline Planned & $105(91.3)$ & $87(87.0)$ & 1.037 & $0.308^{\dagger}$ \\
\hline Unplanned & $10(8.7)$ & $13(13.0)$ & & \\
\hline \multicolumn{5}{|l|}{ Pregnancy type } \\
\hline Natural & $109(94.8)$ & $96(96.0)$ & 1.800 & $0.671^{\ddagger}$ \\
\hline Medical assistance & $6(5.2)$ & $4(4.0)$ & & \\
\hline
\end{tabular}

\section{Table 2. Between-group comparisons of pre- and post-education PSEQ and PAI mean scores}

\begin{tabular}{|c|c|c|c|c|}
\hline First evaluation PSEQ & $121.6 \pm 17.1$ & $122.3 \pm 17.9$ & 0.293 & 0.770 \\
\hline Second evaluation PSEQ & $112.3 \pm 18.3$ & $122.2 \pm 19.6$ & 3.820 & $<0.001$ \\
\hline Second evaluation PAI & $71.7 \pm 8.9$ & $70.1 \pm 8.6$ & 1.374 & 0.171 \\
\hline
\end{tabular}

Table 3. Within-group comparisons of pre- and post-education PSEQ and PAI mean scores

\section{Education group $(n=115)$}

Scales Before education After education

\begin{tabular}{lcccccrrr} 
& Mean \pm SD & Mean \pm SD & $\mathbf{t}$ & $\mathbf{p}$ & Mean \pm SD & Mean \pm SD & t & p \\
\hline PSEQ & $121.6 \pm 17.1$ & $112.3 \pm 18.3$ & 6.514 & $<0.001$ & $122.3 \pm 17.9$ & $122.2 \pm 19.6$ & 0.080 & 0.936 \\
PAI & $68.1 \pm 9.6$ & $71.7 \pm 8.9$ & 6.176 & $<0.001$ & $69.5 \pm 8.7$ & $70.1 \pm 8.6$ & 0.781 & 0.437
\end{tabular}

Paired t test; PAI: Prenatal Attachment Inventory; PSEQ: Prenatal Self Evaluation Questionnaire; SD: Standard Deviation.

\section{Control group $(n=100)$}

\section{Second evaluation}


groups may be related to that women with higher levels of education may be more willing to participate in childbirth education; that they are more aware of their lack of knowledge and experience in the area and are more likely to want to benefit from service offered to them.

When the efficiency of childbirth education was compared between groups, there was a difference between pregnant women participating and not participating in childbirth education. It was determined that mean prenatal adaptation scores were lower in the EG compared to CG, which means their prenatal adaptation was better. According to this result, the first hypothesis was confirmed. In their study on adolescent pregnancies, Aba et al. also found that prenatal adaptation was higher in the group who received antenatal education compared to the group with no antenatal education. ${ }^{[19]}$ Similarly, in their study on nulliparous women, the study of Serçekuş et al. showed that pregnant women who received antenatal education individually and as a group had better prenatal adaptations compared to the pregnant women in the CG. ${ }^{[18]}$ In addition to confirming this hypothesis, this study found significant differences for the EG between pre- and post-education, while there were no significant differences for CG for the first and second evaluations. As opposed to the present study, Aba et al. identified significant differences between the first and second evaluations both in EG and CG. ${ }^{[19]}$ This difference can be attributed to the characteristics of their sample group and the weeks in which the evaluations were carried out (12-37. weeks). In another study, however, it was determined that individual education provided for six hours one month before birth did not affect prenatal adaptation. ${ }^{\text {[29] }}$ This difference in results is believed to be related to that childbirth education, which started in the final trimester of pregnancy and ended before the last month of pregnancy when anxiety was much higher, having a longer duration.

Education in the prenatal period is regarded to be important in improving maternal attachment. ${ }^{[1,11,20,21]}$ Bellieni et al. found that PAI scores of pregnant women in the EG were higher than the pregnant women in the CG after the 1-hour antenatal education of five sessions during the first and second trimesters. ${ }^{[30]}$ Similarly, antenatal education seems to increase attachment in other studies. ${ }^{[1,9,11,21]}$ This finding supports the results of previous studies, and it was determined that education increased prenatal attachment in the EG, whereas prenatal attachment scores were similar in CG in the first and second evaluations. Expectation and motivation are strong factors that influence the learning process. ${ }^{[31]}$ Thus, it can be argued that the pregnant women participating in the EG were more motivated, and therefore, their attachment levels increased. At the same time, the music played during relaxation exercises, baby-related affirmations, and feeling the baby by touching the belly may have positively contributed to the attachment level of the EG. A study conducted showed that listening to music in the prenatal period decreased the anxiety in pregnant women and affected their psychological and cognitive processes positively. ${ }^{[32]}$ However, it was identified that education did not affect PAI scores for EG and CG. Based on this finding, second hypothesis (there is a difference between prenatal attachment level of pregnant women participating and not participating in childbirth education) was rejected. Contrary to this finding presented here, some studies found that antenatal education generated differences between EG and CG in terms of prenatal attachment in favor of EGs. ${ }^{[11,21,30]}$ Differences in this study may be related to variations in content, period and the characteristics of the EG.

Gestational week affects prenatal attachment and prenatal attachment increases in pregnant women parallel to the progress of the pregnancy. ${ }^{[12]}$ It was also found that nulliparity and the absence of high-risk pregnancy increased prenatal attachment. ${ }^{[3,34]}$ In addition, the participation of fathers in education supports prenatal attachment. A study conducted in Turkey determined that prenatal attachment levels of future fathers were lower than those of future mothers and that profoundly affected expectant mothers. ${ }^{[35]}$ Thus, it is important for future fathers to participate in education. These results suggest that factors other than education influence attachment. In the present study, existence of a high level of planned pregnancies in EG and CG, nulliparity, absence of high-risk pregnancies and lack of fathers' participation across both groups may be the cause of similar prenatal attachment levels in both groups.

This study investigated the effects of childbirth education provided during the prenatal period on maternal attachment during the first month postpartum and found similar mean MAI scores in both EG and CG. Therefore, third hypothesis was rejected. Similar to this study, Serçekuş et al. showed that antenatal education did not affect maternal attachment and Van der Walt found that there was no difference at 6th week postpartum in maternal attachment levels of pregnant women who received sensory arousal education in which auditory and tactile stimuli were used and pregnant women who received routine antenatal education. ${ }^{[18,36]}$ In contrast, Toosi et. al. showed that 4-session relaxation education of 90 minutes at 32-35 weeks of gestation increased maternal attachment to the newborn. ${ }^{[37]}$ The difference between the findings of this study and that of Toosi et al. may be related to the periods when the education was provided, and assessments were conducted. ${ }^{[37]}$ Attachment is a process that starts in the prenatal period 
and continues after birth. ${ }^{[13]}$ Studies show that maternalfetal attachment in the third trimester of pregnancy was associated with postpartum mother-infant interaction, and attachment was found to take shape during the period between 6-24 months postpartum. ${ }^{[10,13]}$ In this context, lack of difference in prenatal attachment levels in EG and CG before birth may have affected the subsequent maternal attachment scores similarly. At the same time, maternal attachment was assessed at first month postpartum when mothers may have been more likely to experience physical and psychological problems that may have influenced their attachment. Hence, the attachment may have been influenced by factors other than education.

The main limitation of this study is the inability to randomize the participants with the idea that there will be a high number of losses. Although all EG participants started voluntarily, $40.0 \%$ of them stopped attendance (due to withdrawal, irregular attendance, complications of pregnancy). A high ratio of participants (51.0\%) in CG who withdrew from this study in the prenatal period was related to their irregular prenatal controls and their having the relevant services from different institutions. EG and CG consisted of pregnant women who continued routine antenatal followup recommended by the Ministry of Health in our country. However, the lack of an evaluation of these antenatal follow-ups for both groups was another limitation of this study. Since the program was implemented during working hours, the spouses had no opportunity to attend the education. Another limitation was that visualization, affirmation and relaxation exercises to be done at home by the EG could not be controlled as desired. On the other hand, achieving a sufficient number of powerful samples, providing education with certified trainers and conducting this study during prenatal and maternal periods are the strengths of this study.

\section{CONCLUSION}

The findings showed that the education provided by trainers experienced in childbirth education improved prenatal adaptation but had no effect on prenatal and maternal attachment. Health care professionals should support and encourage families to increase the quality of parent-infant interaction by considering that attachment is a multifaceted process. Childbirth education prepares couples for parenting by increasing their self-confidence. This education provides the ability to cope with problems related to pregnancy, birth, family, and to adapt to physiological and psychological changes. However, it is important to standardize these programs to be provided by experienced midwives and nurses, increase the number of programs and ensure that they are part of routine antenatal care. Also, there is a need for regulations in our country to encourage the participation of fathers in these programs and delivery. Education should also be arranged outside working hours so that working women and all spouses can participate. Midwives and nurses who support antenatal services should participate in these programs to increase their awareness about the subject.

*The study was presented at the $1^{\text {st }}$ International and $2^{\text {nd }}$ National Women's Health Nursing Congress, 23-24 March 2018, Istanbul, Turkey.

**This study was produced from a scientific research project named "Investigating the effects of childbirth education on prenatal, birth and postpartum periods".

\section{Disclosures}

Funding: This study was supported by Bolu Abant İzzet Baysal University, Scientific Research Projects (BAP) Management Unit (Project No: 2015.13.01.937).

Peer-review: Externally peer-reviewed.

Conflict of Interest: None declared.

Ethics Committee Approval: Ethical approval for this study was obtained from Bolu Abant İzzet Baysal University Social Sciences Ethics Committee for Human Research (Approval No: 2015/50 and Approval Date: 31.03.2015,) and Bolu Public Hospitals Association (Approval No: 71924980/770 and Approval Date: 20.07.2015). Participants were assured that participation was voluntary, that they could withdraw from this study any time, and their names would be kept confidentially. Written consent was obtained from all participants.

Authorship Contributions: Concept - N.C.B., B.A., F.A., F.K., S.Y., M.A.T.; Design - N.C.B., F.A., F.K., S.Y.; Supervision - N.C.B., B.A.; Materials - N.C.B., F.K.; Data collection \&/or processing - N.C.B., FA., F.K.; Analysis and/or interpretation - N.C.B., B.A.; Literature search - N.C.B., B.A., F.A.; Writing - N.C.B., B.A., F.A.; Critical review - N.C.B., B.A., F.A., F.K., S.Y., M.A.T.

\section{REFERENCES}

1. Chang S, Park S, Chung C. Effect of Taegyo-focused prenatal education on maternal-fetal attachment and self-efficacy related to childbirth. Taehan Kanho Hakhoe Chi 2004;34:1409_ 15.

2. Serçekuş $P$, Mete $S$. Turkish women's perceptions of antenatal education. Int Nurs Rev. 2010;57:395-401.

3. Bergström $M$, Kieler $H$, Waldenström U. Effects of natural childbirth preparation versus standard antenatal education on epidural rates, experience of childbirth and parental stress in mothers and fathers: a randomised controlled multicentre trial. BJOG 2009;116:1167-76.

4. Firouzbakht $M$, Nikpour M, Khefri S, Jamali B, Kazeminavaee F, Didehdar M. The Effectiveness of Prenatal Intervention on Pain 
and Anxiety during the Process of Childbirth-Northern Iran: Clinical Trial Study. Ann Med Health Sci Res 2015;5:348-52.

5. Demirbaş $\mathrm{H}$, Kadıoğlu $\mathrm{H}$. Adaptation to pregnancy in prenatal period women and factors associated with adaptation. MÜSBED 2014;4:200-6.

6. Beydağ KD, Mete $S$. Prenatal Kendini Değerlendirme Ölçeğinin Geçerlik ve Güvenirlik Çalışması. Atatürk Üniversitesi Hemşirelik Yüksekokulu Dergisi 2008;11:16-24.

7. Karabulut Ö, Coşkuner Potur D, Doğan Merih Y, Cebeci Mutlu $\mathrm{S}$, Demirci N. Does antenatal education reduce fear of childbirth?. Int Nurs Rev 2016;63:60-7.

8. Beydağ KD. Adaptation to motherhood in the postpartum period and the nurse's role. TSK Koruyucu Hekimlik Bülteni 2007;6:479-84.

9. Kartal YA, Karaman T. Effect of birth preperation training on prenatal attachment and depression. Zeynep Kamil Tıp Bülteni 2018;49:85-91.

10. Siddiqui A, Hägglöf B. Does maternal prenatal attachment predict postnatal mother-infant interaction?. Early Hum Dev 2000;59:13-25.

11. Abasi $E$, Tafazzoli $M$, Esmaily $H$, Hasanabadi $H$. The effect of maternal-fetal attachment education on maternal mental health. Turkish Journal of Medical Sciences 2013;43:815-20.

12. Elkin N. Levels of prenatal attachment in pregnant women and factors affecting it. Sted 2015;24:230-6.

13. Soysal AŞ, Bodur Ş, İşeri E, Şenol S. Bebeklik dönemindeki bağlanma sürecine genel bir bakış. Journal Clin Psy 2005;8:8899.

14. Weis K, Lederman R. Prenatal spousal military deployment and maternal prenatal adaptation as predictors of postpartum maternal-infant attachment. South Online J Nurs Res 2010;10:228-44.

15. Yılmaz SD, Beji NK. Prenatal Bağlanma Envanterinin Türkçe'ye Uyarlanması: Güvenilirlik ve Geçerlilik Çalışması. Anadolu Hemşirelik ve Sağlık Bilimleri Dergisi 2013;16:103-9.

16. Lindgren K. Relationships among maternal-fetal attachment, prenatal depression, and health practices in pregnancy. Res Nurs Health 2001;24:203-17.

17. Güney $E$, Uçar T. Effect of the fetal movement count on maternal-fetal attachment. Jpn J Nurs Sci 2019;16:71-9.

18. Serçekuş $P$, Mete $S$. Effects of antenatal education on maternal prenatal and postpartum adaptation. J Adv Nurs 2010;66:9991010.

19. Aba YA, Kömürcü N. Antenatal Education on Pregnant Adolescents in Turkey: Prenatal Adaptation, Postpartum Adaptation, and Newborn Perceptions. Asian Nurs Res (Korean Soc Nurs Sci) 2017;11:42-9.

20. Salehi K, Salehi Z, Shaali M. The effect of education of fetal movement counting on maternal-fetal attachment in the pregnant women: A randomized controlled clinical trial. International Journal of Pediatrics 2017;5:4699-706.
21. Baghdari N, Sadeghi Sahebzad E, Kheirkhah M, Azmoude E. The Effects of Pregnancy-Adaptation Training on MaternalFetal Attachment and Adaptation in Pregnant Women With a History of Baby Loss. Nurs Midwifery Stud 2016;5:e28949.

22. Lederman RP, Lederman E, Work BA Jr, McCann DS. Relationship of psychological factors in pregnancy to progress in labor. Nurs Res 1979;28:94-7.

23. Muller ME. Development of the Prenatal Attachment Inventory. West J Nurs Res. 1993;15:199-215.

24. Müller ME. A questionnaire to measure mother-to-infant attachment. J Nurs Meas. 1994;2:129-41.

25. Kavlak O, Şirin A. The Turkish version of maternal attachment inventory. International Journal of Human Sciences 2009;6:188-202.

26. Tabachnick BG, Fidell LS. Using multivariate statistics. 6 th ed. Boston: Pearson; 2013.

27. Coşar F, Demirci N. The effect of childbirth education classes based on the philosophy of lamaze on the perception and orientation to labour process. S.D.Ü. Sağlık Enstitüsü Dergisi 2012;3:18-30.

28. Mete $S$, Çiçek Ö. Labor support: An aplication is starting again come into prominence. Bezmialem Science 2017;6:138-42.

29. Hamilton-Dodd C, Kawamoto T, Clark F, Burke JP, Fanchiang SP. The effects of a maternal preparation program on motherinfant pairs: a pilot study. Am J Occup Ther 1989;43:513-21.

30. Bellieni CV, Ceccarelli D, Rossi F, Buonocore G, Maffei M, Perrone $S$, Petraglia $F$. Is prenatal bonding enhanced by prenatal education courses? Minerva Ginecol 2007;59:125-9.

31. Ahldén I, Ahlehagen S, Dahlgren LO, Josefsson A. Parents' expectations about participating in antenatal parenthood education classes. J Perinat Educ 2012;21:11-7.

32. Arabin B, Jahn M. "Need for interventional studies on the impact of music in the perinatal period: results of a pilot study on women's preferences and review of the literature". J Matern Fetal Neonatal Med 2013;26:357-62.

33. Yılmaz SD, Beji NK. Levels of coping with stres, depression and prenatal attachment and affecting factors of pregnant women. Genel Tip Dergisi 2010;20:99-108.

34. Wright J, Belanger C, Dulude D. The effects of pregnancy complications on the parental adaptation process. Journal of Reproductive and Infant Psychology 2000;18:5-20.

35. Ustunsoz A, Guvenc G, Akyuz A, Oflaz F. Comparison of maternal-and paternal-fetal attachment in Turkish couples. Midwifery 2010;26:e1-e9.

36. Van der Walt MM. Prenatal stimulation program to enhance postnatal bonding (dissertation). South Africa: North-West University. 2014.

37. Toosi M, Akbarzadeh M, Sharif F, Zare N. The reduction of anxiety and improved maternal attachment to fetuses and neonates by relaxation training in primigravida women. Womens Health Bulletin 2014;1:e18968. 